\title{
Tyrosine Measurement
}

National Cancer Institute

\section{Source}

National Cancer Institute. Tyrosine Measurement. NCI Thesaurus. Code C122159.

The determination of the amount of tyrosine present in a sample. 